\title{
A CONDIÇÃO HUMANA DE HANNAH ARENDT CHEGA AOS 60 ANOS: possibilidades e limites da sua contribuição em um cenário de conjunção de crises
}

\author{
Ingrid Cyfer* \\ Denise Vitale ${ }^{* *}$ \\ Renata Nagamine ${ }^{* * *}$ \\ INTRODUÇÃO
}

\begin{abstract}
A segunda década do século XXI chega ao fim com um sinal de alerta. De repente, diante de um novo vírus que se alastra globalmente causando uma pandemia, os países se fecham e o mundo se retrai, com efeitos paralisantes e distópicos, mas também abrindo espaço para pararmos para pensar. Confinados em nossos espaços domésticos, somos confrontados com questões limites da nossa existência, do ponto de vista individual e coletivo, e até mesmo como espécie. As relações natureza-cultura e indivíduo-sociedade, cernes do pensamento social moderno, passam a nortear nossas indagações mais imediatas. Ao mesmo tempo, a

\footnotetext{
* Universidade Federal de São Paulo (UNIFESP). Departamento de Ciências Sociais.

Estr. do Caminho Velho, 333. Jardim Nova Cidade. Cep: 07252-31. Guarulhos - São Paulo - Brasil. icyfer@unifesp.br. orcid.org/0000-0002-0992-6403

** Universidade Federal da Bahia. Instituto de Humanidades, Artes e Ciências prof. Milton Santos. Programa de Pós-Graduação em Relações Internacionais.

Avenida Barão de Jeremoabo s/n, campus Ondina (Paf V). Cep: 40170115. Salvador - Bahia - Brasil. denise,vitale@ufba.br orcid.org/0000-0002-0777-3642

*** Universidade Federal da Bahia. Instituto de Humanidades, Artes e Ciências Professor Milton Santos. Avenida Barão de Jeremoabo s/n, campus Ondina (Paf V). Cep: 40170115. Salvador - Bahia - Brasil. renagamine@gmail.com orcid.org/0000-0003-2447-5548
}

cooperação entre os indivíduos de cada cidade e entre os diversos países torna-se peça central para se vislumbrar qualquer solução, que exige o distanciamento social mútuo e o compartilhamento de dados e estudos para se chegar a uma vacina, necessária a toda a humanidade.

Esta intrincada conjunção de problemas complexos - o contágio, a doença, a vacina, a paralisação da economia, seu potencial politicamente desestabilizador - coloca-se em um contexto político de acirrada polarização, marcado pela ascensão de grupos de extrema-direita na Europa e no continente americano, que ganhou força nos últimos anos, sobretudo com o Brexit e a campanha e eleição do atual presidente dos Estados Unidos, Donald Trump. No Brasil, a falta de respostas adequadas à crise política que eclodiu nas jornadas de junho de 2013 também levou a um processo de radicalização, com a articulação da extrema-direita dentro do Judiciário, em operações judiciais de combate à corrupção, e a eleição de Jair Bolsonaro, em 2018. Às crises sanitária, ambiental e econômica associadas à pandemia soma-se, assim, uma crise política de múltiplas dimensões, comprometendo de conversas entre ami- 
gos, ao funcionamento das instituições, e de grande relevância, porque só a partir dela soluções para as demais crises podem ser pensadas.

Trata-se, portanto, de um momento bastante paradoxal. Ao mesmo tempo em que precisamos de intensa e ampla cooperação entre todos os atores globais para o combate a um problema comum à humanidade - o contagioso vírus SARS-Cov-2 -, vivemos, em países democráticos, uma conjuntura política extremista, propícia a alianças de guerra, do tipo amigo-inimigo, e, marcada pela dificuldade ou quase impossibilidade do diálogo. Pensar com Hannah Arendt, nesse contexto, é convidar a conversas acerca de uma pensadora anti-dogmática, intelectualmente independente, que se debruçou sobre os problemas de seu tempo, mas também apreendeu, ainda nos anos 1950, o que hoje nos parecem ser formas incipientes dos problemas que nos afligem, daqueles que se anunciam, e apostou na reabilitação da política como o único caminho para a busca de soluções a eles.

Arendt foi polêmica e reconhecida por seus pares ainda em vida, mas o alcance e a proficuidade que seus escritos encontram na atualidade lhe teriam sido surpreendentes. Seus livros conheceram inúmeras traduções em todo o mundo, muitas das quais para o português. No Brasil, o legado de Arendt tem sido consistentemente estudado desde os anos 1990, sendo o seu pensamento objeto de inteㄱ resse de pesquisadores nos campos da filosofia ลे política e moral, da teoria política e da socioloจे gia, bem como da filosofia do direito e do direito internacional. Outro sinal do longo alcance f de suas ideias pode ser o fato de sua obra estar sendo retomada no debate acadêmico mais recente para discutir problemas teóricos e políticos do nosso tempo.

A ampla bibliografia de Arendt é composta principalmente de ensaios, escritos em resposta a acontecimentos contemporâneos seus que lhe desafiaram o pensamento. Dois dos seus títulos mais conhecidos e importantes são, no entanto, obras fechadas: Origens do totalitarismo, publicada na íntegra em 1951, e A condição humana, de 1958.

Uma das obras mais importantes do século XX, A condição humana pode ser lida como uma crítica da modernidade a partir dos antigos, os gregos e os romanos, e a tradição judaico-cristã. Para parte de seus leitores, a crítica de Arendt é imbuída de nostalgia e bem sucedida em assinalar as perdas da modernidade. Nessa leitura, o seu tom seria de desalento. Outros de seus leitores enfocam a saída indicada por Arendt, a ação política, que seguiria sendo uma possibilidade a despeito da ascensão do social. Em qualquer hipótese, cabe perguntar: por que mais do que nunca nos debruçamos sobre os escritos arendtianos em geral e A condição humana, em particular, no momento em que ela completa sessenta anos? Como entender a centralidade que sua obra ganhou nos debates mais recentes da Teoria Crítica, apesar de Arendt ter-se mantido intencionalmente distante de Theodor Adorno e Max Horkheimer?

As interpretações contemporâneas da obra de Arendt são múltiplas e conflituosas entre si, algumas enfatizando o caráter intersubjetivista de sua concepção de política, outras destacando sua dimensão agonística, além daquelas que exploram a tensão entre ambos. Além disso, há apropriações da obra arendtiana que encontram em seu pensamento elementos para discutir questões que não estavam em seu radar, como o feminismo e a psicanálise.

Apesar da diversidade na leitura contemporânea do pensamento de Arendt, há uma questão que costuma perpassá-la: a pluralidade humana entendida como expressão do "duplo aspecto da igualdade e da distinção”. Essa duplicidade, por sua vez, implica uma concepção de ação entendida como agir em concerto, como uma ação em que "as pessoas estão com as outras, nem pró nem contra elas, isto é, o puro estar junto dos homens (sic)" (Arendt, 2020, p.223).

O agir em concerto, como se vê, é o oposto da polarização, na forma como a descrevemos, que em última instância recusa 
tanto a distinção que nos singulariza quanto a igualdade que nos permite compreender uns aos outros (Arendt, 2020, p.217). Ser apenas a favor ou contra outras pessoas reduz a ação a um meio para atingir determinado fim, para alcançar objetivos próprios em prejuízo do inimigo (Arendt, 2020, p. 223). Essa rivalidade da guerra, que divide as pessoas em grupos dicotômicos, torna a ação desprovida de qualquer sentido (Arendt, 2020, p.224). No entanto, a violência que destrói a pluralidade, que ergue barreiras intransponíveis entre as pessoas, não é jamais um fato consumado e irreversível, pois cada nascimento na teia de relações humanas traz consigo a possibilidade da criação do novo, do inesperado, do milagre.

Nesse sentido, talvez possamos mesmo dizer que somente um milagre pode nos livrar da catástrofe política que estamos vivendo. Mas, em sua versão arendtiana, o milagre não viria nem de Deus, nem de seus enviados, e sim da mais humana das atividades humanas fundamentais, a ação, que cria um espaço entre (in between) polos construídos e reforçados por discursos de ódio.

Este dossiê temático tem por escopo oferecer uma visão plural e interdisciplinar das questões levantadas acima, em busca de aprofundar a reflexão sobre a obra de Hannah Arendt e lançar luz sobre as apropriações de seu pensamento por algumas das principais referências do pensamento político do século XXI, em diferentes planos, o debate político contemporâneo.

O artigo de Renata Nagamine. e Denise Vitale analisa o conceito de espaço público no pensamento de Hannah Arendt, a partir de $A$ condição humana no contexto da pandemia de Covid19. Tratando-se de um fenômeno em andamento, as autoras o compreendem como uma experiência liminar, que nos convida a pensar as reconfigurações do espaço e do tempo. Em 2020, o esvaziamento das cidades, a paralisação da economia, a insuficiência da satisfação das necessidades vitais para larga parte da humanidade, a circulação de notícias falsas e o aparecimento de novas formas de in- teração tem causado mudanças significativas no espaço público até então reconhecido por nós. Arendt fornece elementos para pensar os desafios postos pela pandemia e para imaginar em sua travessia o mundo que não é ainda.

Yara Frateschi propõe uma análise do livro Situating the self: gender, community and postmodernism in contemporary ethics (1992), de Seyla Benhabib. Seu objetivo é salientar que os artigos ali reunidos revelam que a influência arendtiana no pensamento de Benhabib não se limita às suas conhecidas críticas aos excessos racionalistas da tradição universalista moderna. Frateschi argumenta que esse livro indica que a influência mais radical de Hannah Arendt na obra de Benhabib está na crítica arendtiana à filosofia política ocidental.

O artigo de André Duarte aborda a leitura que Benhabib faz do pensamento arendtiano, assim como Frateschi. Duarte tem, no entanto, outra proposta. Seu objetivo é discutir a noção de "direito a ter direitos" analisando a interpretação de Benhabib, que a aproxima de um cosmopolitismo neokantiano. Valendo-se da apropriação que Judith Butler faz de Arendt em seus trabalhos mais recentes, Duarte contrapõe à leitura de Benhabib a centralidade da dimensão político-performativa no pensamento arendtiano, destacando sua contribuição para refletirmos sobre o atual contexto de privação de direitos.

Ingrid Cyfer também se inspira na leitura que Judith Butler faz de Hannah Arendt, mas o faz no contexto de uma discussão sobre as conexões que estabelece entre a concepção de narrativa arendtiana, a filosofia política feminista de Adriana Cavarero e a psicanálise relacional de Jean Laplanche. Com base nessas articulações propostas por Butler, Cyfer

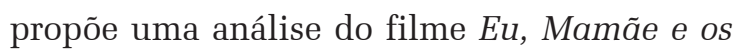
Meninos em que discute a relação entre narrativa, psicanálise e subjetivação tendo em vista o vínculo entre ética e política que o filme nos convida a explorar.

A esses artigos que discutem a apropriação contemporânea de Arendt, seguem-se con- 
tribuições que visam examinar temas e conceitos arendtianos explorando tensões internas à própria obra da autora. Nessa linha, Adriano Correia propõe-se a discutir o tema do perdão em Hannah Arendt, buscando salientar que seu posicionamento se modifica significativamente ao longo da década de 1950, deslocando sua ênfase na relação entre o perdão e o cristianismo para privilegiar a relação entre perdão, ação e sua imprevisibilidade. $\mathrm{O}$ dossiê se encerra com o artigo de Rodrigo Chacón, que propõe que a obra $A$ condição humana, considerada em seu conjunto, apresenta antes uma reflexão sobre as condições de possibilidade das experiências humanas de sentido do que uma referência para pensarmos modelos de política. Chácon argu- menta, então, que essa obra corresponde a uma investigação fenomenológica cujas premissas indicam tanto seus aparentes pontos cegos, quanto seu potencial crítico.

Boa leitura!

Recebido em 23 de julho 2020 Aceito em 30 de agosto de 2020

\section{REFERÊNCIA}

ARENDT, H. A Condição Humana. Tradução Roberto Raposo. Revisão técnica Adriano Correia- 13 ed. Rio de Janeiro: Forense, [1958] 2020.

Ingrid Cyfer - Pós- Doutorado em Dartmouth College- EUA no Departamento de Filosofia. Doutorado em Ciência Política pela USP, com estágio doutoral na New School for Social Research. Professora do Departamento de Ciências Sociais da Universidade Federal de São Paulo. Integra o Núcleo de Pesquisa Teoria Crítica e Psicanálise, vinculado ao Núcleo Direito e Democracia do CEBRAP. É membro do Departamento de Formação em Psicanálise do Instituto Sedes Sapientiae. Suas mais recentes publicações são: Cyfer, I. "A bruxa está solta: os protestos contra a visita de Judith Butler ao Brasil à luz de sua reflexão sobre ética, política e vulnerabilidade”. Cadernos Pagu (53), 2018; Cyfer, Ingrid. Teoria Crítica e Feminismo: discutindo a relação. In: Vitale, Denise; Nagamine, R. (Org.). Gênero, Direito e Relações Internacionais: debates de um campo em construção. 1ed.Salvador, Bahia: EDUFBA, 2018, v. , p. 7-25; Cyfer, I "Arendtian Narratives: Adriana Cavarero and Judith Butler on the agency and opacity of the self” in Rosenfield, K; Silva, Felipe Gonçalves (Orgs.) Martin Heidegger e Hannah Arendt no seu tempo - e no nosso. Porto Alegre, RS: Editora Fi, 2019; Cyfer, Ingrid. "What's the trouble with humanity? A feminist critique of Judith Butler's ethics of vulnerability” in Teixeira, M e Bueno, A. (Special Section: The Politics of Social Suffering). Digithum, N. 23, 2019.

Denise Vitale - Pós-Doutora no European University Institute. Doutora em Direito pela Universidade de São Paulo. Professora do Instituto de Humanidades, Artes e Ciências prof. Milton Santos da Universidade Federal da Bahia. Coordenadora do Programa de Pós-Graduação em Relações Internacionais da Universidade Federal da Bahia. Pesquisadora do CNPQ (PQ2). Integra os Grupos de Pesquisa Laboratório de Análise Política Mundial e Território, Poder e Desigualdades Sociais, desenvolvendo pesquisas na área de direitos humanos, meio ambiente, democracia e gênero. Suas mais recentes publicações são as co-organizações das coletâneas Gênero, Direito e Relações Internacionais, Salvador: Edufba, 2018, em parceria com Renata Nagamine e Dicionário Temático Desenvolvimento e Questão Social: 110 problemáticas contemporâneas, São Paulo: Annablume, 2020, coordenado por Anete Ivo.

Renata R. V. K. Nagamine - Doutora e Mestre em direito internacional pela Faculdade de Direito da USP. Professora e pós-doutoranda (PNPD-CAPES) do Programa de Pós-Graduação em Relações Internacionais da UFBA. É pesquisadora no Centro Brasileiro de Análise e Planejamento (Cebrap), desenvolvendo pesquisas na área de religião e espaço público no Brasil contemporâneo. Suas mais recentes publicações são: Human Rights, Humanitarian Law and State Power. Revista de Direito Internacional, v. 17, p. 418431, 2020, em coautoria com João Henrique Roriz, e Os direitos de pessoas LGBT na ONU (2000-2016). Sexualidad, Salud y Sociedad (RIO DE JANEIRO), v. 31, p. 28-56, 2019. Também co-organizou a coletânea Gênero, direito e relações internacionais, em parceria com Denise Vitale. 